\title{
Favorable Postoperative Evolution after Late Surgical Repair of Truncus Arteriosus Type 1: A Case Report
}

\author{
Daniela Toma'1, Carmen Corina Șuteu', Rodica Togănel² \\ 1 Department of Pediatric Cardiology, Emergency Institute for Cardiovascular Diseases and Transplantation, Tîrgu Mures, Romania \\ 2 Illrd Department of Pediatric Cardiology, University of Medicine and Pharmacy, Tîrgu Mureș, Romania
}

\section{CORRESPONDENCE}

Carmen Corina Șuteu

Str. Gheorghe Marinescu nr. 50

540136 Tîrgu Mures, Romania

Tel: +40745534554

E-mail: suteucarmen@yahoo.com

\section{ARTICLE HISTORY}

Received: April 13, 2018

Accepted: June 12, 2018
Daniela Toma • Str. Gheoghe Marinescu nr. 50, 540136 Tîrgu Mureș, Romania. Tel: +40 745652 688, E-mail: tomadaniela94@yahoo.com

Rodica Togănel • Str. Gheoghe Marinescu nr. 50 540136 Tîrgu Mureș, Romania. Tel: +40 745310991 E-mail: rodicatoganel@yahoo.com

\begin{abstract}
Truncus arteriosus communis (TA) is a rare cyanotic congenital heart defect, in which the aorta and the pulmonary artery have not been separated during the normal development of the fetal heart, so a single truncal artery is arising from the base of the heart. Most patients with TA present within the first weeks of life with heart failure. This anomaly is an important cause of pulmonary arterial hypertension. Corrective surgery is indicated in the first 3 months of life, to avoid the development of severe pulmonary arterial hypertension. We report the case of a 12 -monthold male infant diagnosed by echocardiography with truncus arteriosus type 1 in whom, based on hemodynamic data, surgical treatment could be performed at the age of 1 year.
\end{abstract}

Keywords: truncus arteriosus, pulmonary arterial hypertension, children

\section{INTRODUCTION}

Truncus arteriosus (TA) is a rare cyanotic congenital cardiac malformation characterized by a single common artery, which emerges from the heart through a single semilunar truncal valve and delivers blood to the systemic, pulmonary, and coronary circulation. Pulmonary arteries emerge from the common arterial trunk, after the origin of the coronary arteries and proximal to the first brachiocephalic branch of the aortic arch. ${ }^{1-3}$ Characteristically, there is a misalignment over a large ventricular septal defect. This anomaly is often associated with various disorders such as truncal valve stenosis or regurgitation, coronary artery anomalies, atrial septal defect, aberrant subclavian arteries, persistent superior vena cava and a patent ductus arteriosus.

There are several clinical classifications that describe the various forms of TA; the most commonly used are the Collett and Edward classification and the Van Praagh classification. ${ }^{2}$

Truncus arteriosus is a life-threatening condition, as its natural history bears a mortality rate of $80 \%$ in the first year of life and especially during infancy. ${ }^{2}$ The 


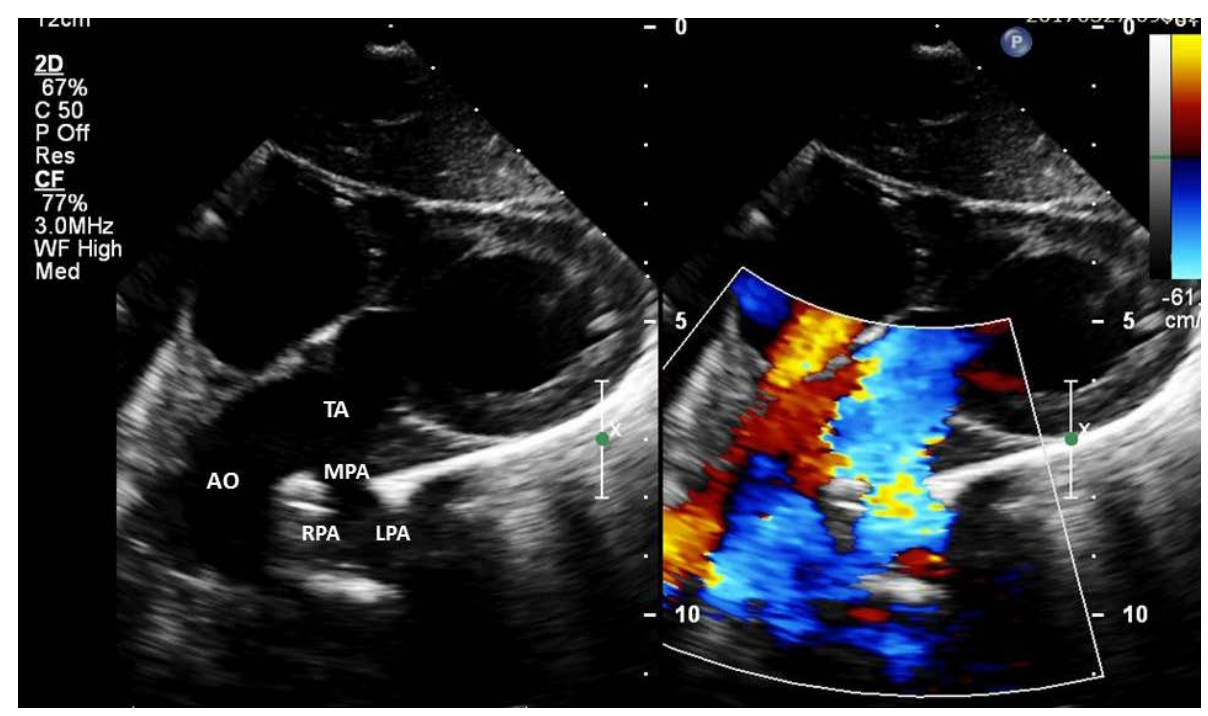

FIGURE 1. Echocardiography (2D and color Doppler) - subcostal view, showing a single overriding great vessel arising from the heart and the truncus of pulmonary artery emerging from the common arterial trunk. MPA - main pulmonary artery, LPA - left pulmonary artery, RPA - left pulmonary artery, AO - aorta

pathophysiology and the clinical manifestations of TA are particularly dependent on the volume of pulmonary blood flow, assessed by the pulmonary vascular resistance (PVR) and the degree of truncal valve regurgitation. There is mixing of systemic and pulmonary blood at the intracardiac level, resulting in mild or moderate cyanosis. In the first weeks of life, PVR decreases to normal values, leading to pulmonary fluid overload and heart failure. The severity of heart failure is increased in cases with significant truncal valve regurgitation. Corrective cardiac surgery is recommended in the first 3 months of life. In surgically uncorrected cases, pulmonary vascular obstructive disease may develop after the age of 6 months.

\section{CASE REPORT}

We report the case of a 12-month-old male infant who was referred to our department with a history of respiratory distress, difficulty in breathing, tachypnea, poor feeding, and failure to thrive. On admission, the clinical examination revealed mild cyanosis, peripheral oxygen saturation was $94 \%$, respiratory rate was 70 respirations per minute, heart rate was 150 beats/minute, blood pressure was $90 / 48 \mathrm{mmHg}$, and there was a loud and single second heart sound on auscultation and a harsh systolic murmur (3/6) at the lower left sternal border. The liver was enlarged, approximately $2 \mathrm{~cm}$ below the right costal margin. His weight was $6.5 \mathrm{~kg}$ ( $80 \%$ of the expected weight). The hemoglobin concentration was $12.2 \mathrm{~g} / \mathrm{dL}$, and the hematocrit value was $34 \%$.
The electrocardiogram showed peaked $\mathrm{P}$ wave and biventricular hypertrophy, and the chest X-ray showed cardiomegaly with prominent right cardiac cavities and increased pulmonary vascular markings.

The echocardiography demonstrated the typical findings of TA: a single arterial stem giving rise to the pulmonary trunk with normal-sized pulmonary arteries arising from the main pulmonary artery segment (Figure 1). A large ventricular septal defect with bidirectional shunt was present. The echocardiographic examination revealed also a quadricuspid truncal valve with mild regurgitation, a normal origin of the coronary arteries, and a normal aortic arch.

The computed tomography (CT) examination confirmed the diagnosis of TA type I (Figure 2A, 2B).

Considering the pathophysiology of this complex congenital heart disease and that the diagnosis was made at the age of 12 months, a hemodynamic investigation was indicated to evaluate the pulmonary pressure and the PVR. The cardiac catheterization revealed quasi-systemic pressures in the pulmonary circulation with a mean pulmonary artery pressure of $47 \mathrm{mmHg}$, with reactive PVR $\left(3.82 \mathrm{UW} / \mathrm{m}^{2}\right.$ in atmospheric air and $2.25 \mathrm{~W} / \mathrm{m}^{2}$ after administration of nitric oxide). These findings indicated the need for surgical correction.

A standard method of TA repair was performed with the termination of the ventricular septum defect, separation of the pulmonary arteries from the primitive truncus, and restoration of the right ventricle and pulmonary artery continuity using a $15 \mathrm{~mm}$ Contegra conduit. The 

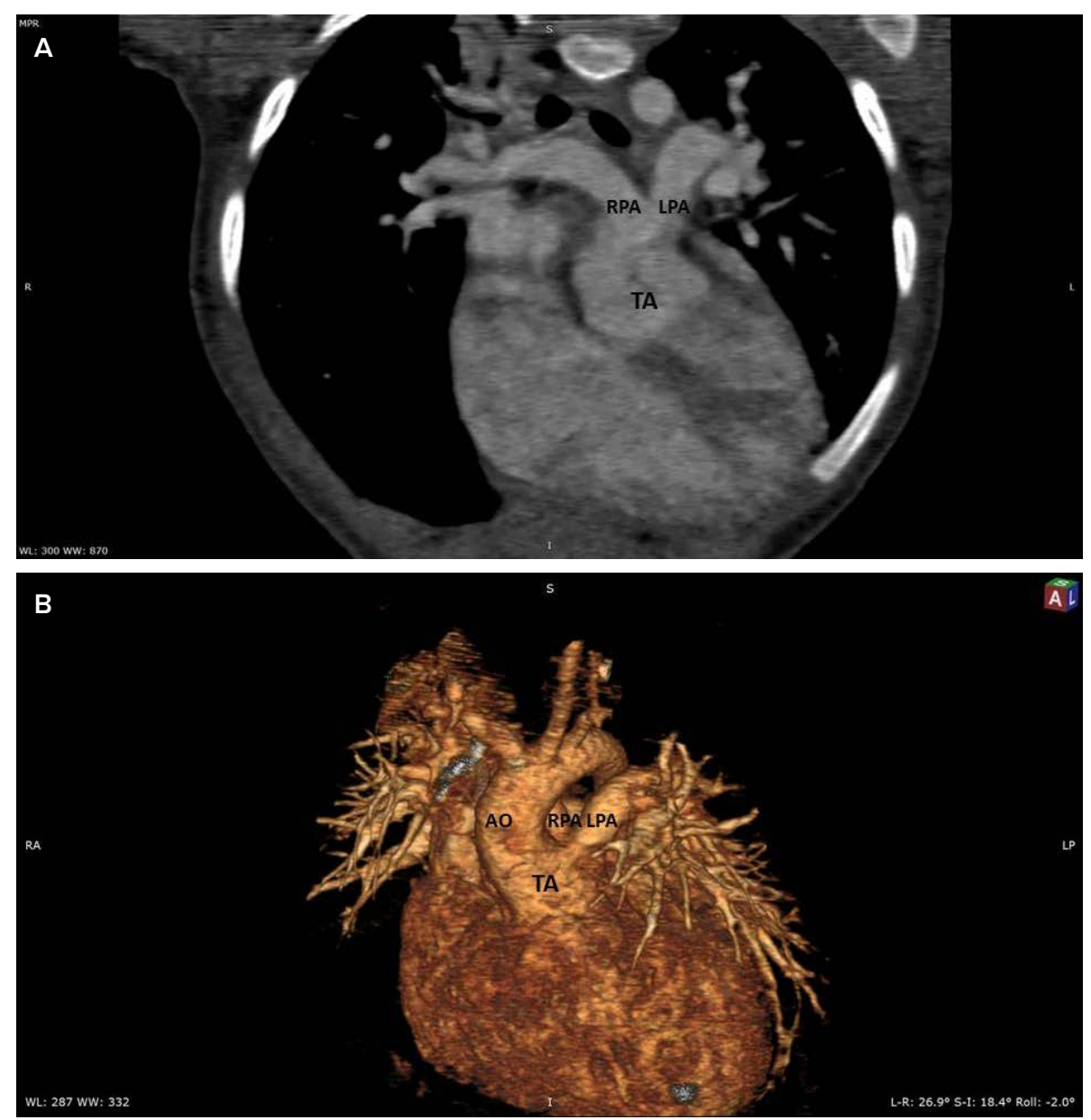

FIGURE 2. Computed tomography (A - sagittal image; $\mathbf{B}-3 \mathrm{D}$ reconstruction) showing a truncus arteriosus communis type I image with a single arterial trunk (TA) giving rise to pulmonary trunk which in turn gave rise to right (RPA) and left pulmonary artery (LPA). AO aorta

surgery was uneventful. Postoperatively, the patient presented symptoms that indicated a low cardiac output due to biventricular dysfunction, requiring the administration of inotrope agents, and pulmonary arterial hypertension (PAH) crises, requiring pulmonary vasodilator therapy consisting of nitric oxide and sildenafil, a phosphodiesterase type 5 inhibitor.

The patient was discharged 20 days after cardiac surgery in optimal condition. The echocardiogram at the time of hospital discharge showed the pulmonary bioprosthesis with a gradient of $12 \mathrm{mmHg}$ and mean regurgitation, mild aortic regurgitation, a ventricular septal defect patch with a small residual left-to-right shunt, and mild tricuspid regurgitation with a gradient of $40 \mathrm{mmHg}$, with recovery of biventricular function.

The echocardiographic examination performed at 1 year after the corrective cardiac surgery showed good function and no signs of residual pulmonary arterial hypertension.

\section{DISCUSSIONS}

TA is an uncommon lesion, with a prevalence of 0.056 to 0.03 in every 1000 births, described as a single arterial stem emerging from the heart, which in turn gives rise to the pulmonary trunk in various ways. ${ }^{4-8}$ TA belongs to the group of ectomesenchymal tissue migration anomalies caused by the aberrant migration of neural crest cells through the branchial arch vessels during cardiogenesis. ${ }^{9,10}$

Chromosomal abnormalities are detectable in $8.7 \%$ of cases of TA. Di George syndrome and 22q11 chromosome microdeletion were reported in more than $30-50 \%$ of cases. ${ }^{411-13}$ In our report, there was no chromosomal disorder present.

Several cases of prenatal diagnosis have been reported, but in most cases the diagnosis is made during the neonatal period, ${ }^{14-16}$ when it is important to differentiate TA from other cardiac disorders that cause early heart failure and 
neonatal sepsis. Failure to thrive, respiratory infections, dyspnea, cyanosis, and clinical signs of congestive cardiac failure are the common features. The electrocardiogram usually shows right axis deviation and right ventricular preponderance, and the chest radiography typically shows cardiac enlargement with an increase in the pulmonary vascular markings.

Diagnosis is achieved by echocardiography, which can identify the type of truncus, the morphology and functionality of the truncal valve, and the physiologic consequences of the cardiac disease. ${ }^{8}$

Due to the advantages of echocardiography, cardiac catheterization with angiography is indicated when pulmonary vascular disease is suspected and to evaluate associated lesions.

The hemodynamic consequences of a common TA may predispose to the development of pulmonary arterial hypertension; for this reason, the corrective operation is indicated before the age of 3 months in order to avoid the development of severe pulmonary vascular obstructive disease. ${ }^{3,17}$ Niwa et $a l$. reported a one-year survival rate of over $80 \%$ in patients who received surgical correction during the neonatal period. ${ }^{18-23} \mathrm{~A}$ delay in the surgical treatment is associated with the risk of postoperative $\mathrm{PAH}$ crisis and cardiac failure..$^{22,24,25}$ Porter et al., in a case series of uncorrected patients, reported a mean period of survival of 5 weeks and a survival rate of only $15 \%$ at the age of 1 year. ${ }^{26}$ Marcelletti et al. concluded that all patients who survive beyond the first year of life, will develop pulmonary vascular obstructive disease. ${ }^{18,27}$

During the postoperative assessment, a careful followup for pulmonary hypertension and truncal conduit patency is needed.

The reported case is one of the few cases diagnosed with TA reported in the literature, in which surgical correction could be performed at the age of 1 year because hemodynamic data did not document the presence of pulmonary vascular obstructive disease. Pulmonary arterial hypertension could seriously complicate the postoperative course of pediatric patients. Although the PAH crises complicated the immediate postoperative evolution, the subsequent evolution of the patient was favorable, and the echocardiography performed at 1 year after surgery indicated no significant residual lesions.

\section{ETHICAL CONSIDERATIONS}

The manuscript is coherent with the ideologies stated within the Declaration of Helsinki. The patient's legal guardian signed an informed agreement and agreed to the publication of his data. The study has been approved by the ethics committee of the University of Medicine and Pharmacy of Tîrgu Mureș, Romania.

\section{CONCLUSIONS}

Truncus arteriosus is a complex cardiac disease, in which primary surgical repair should be performed during the neonatal period in order to avoid the development of severe $\mathrm{PAH}$. The diagnosis is generally confirmed by echocardiography. The management should to be individualized according to the age of the patient, the anatomical type of the TA, the associated lesions, and the hemodynamic consequences.

\section{CONFLICT OF INTEREST}

None declared.

\section{REFERENCES}

1. Yang X, Wang L, Lunhao Li, Yu Z, Xiao C. The Imbalance of Lymphocyte Subsets and Cytokines: Potential Immunologic Insights into the Pathogenesis of Chronic Dacryocystitis. Investigative Ophthalmology \& Visual Science. 2018;59:1802-1809.

2. Costea CF, Dumitrescu GF, Turliuc MD, et al. A 16-year retrospective study of dacryocystitis in adult patients in the Moldavia Region, Romania. Romanian Journal of Morphology and Embryology. 2017;58:537-544.

3. Lefebvre DR, Dhar S, Lee I, Allard F, Freitag SK. External dacryocystorhinostomy outcomes in patients with a history of dacryocystitis. Digital Journal of Ophthalmology. 2015;21:1-22.

4. Krishna Y, Sarah E. Lacrimal Sac Tumors-A Review. Asia-Pacific Journal of Ophthalmology. 2017;6:173-178.

5. Litschel R, Siano M, Tasman AJ, Cogliatti S. Nasolacrimal duct obstruction caused by lymphoproliferative infiltration in the course of chronic lymphocytic leukemia. Allergy \& Rhinology (Providence). 2015;6:191-194.

6. Krishna Y, Irion LD, Karim S, Dharmsena A, McCormick A, Coupland SE. Chronic Lymphocytic Leukaemia/ Small-Cell Lymphocytic Lymphoma of the Lacrimal Sac: A Case Series. Ocular Oncology and Pathology. 2017;3:224-228.

7. Dores GM, Anderson WF, Curtis RE. Chronic lymphocytic leukaemia and small lymphocytic lymphoma: overview of the descriptive epidemiology. British Journal of Hematology. 2007;139:809-819.

8. Parmar DN, Rose GE. Management of lacrimal sac tumours. Eye (London, England). 2003;17:599-606.

9. Kitaguchi Y, Takahashi Y, Mupas-Uy J, Takahashi E, Kakizaki H. Primary Marginal Zone B-Cell Lymphoma of the Mucosa-Associated Lymphoid Tissue of the Lacrimal Sac Found with Epiphora: A Case Report. Case Reports in Ophthalmology. 2016;7:148-154.

10. Yip CC, Bartley GB, Habermann TM, Garrity JA. Involvement of the lacrimal drainage system by leukemia or lymphoma. Ophthalmic Plastic and Reconstructive Surgery. 2002:18:242-246.

11. Koturović Z, Knežević M, Rašić DM. Clinical significance of routine lacrimal sac biopsy during dacryocystorhinostomy: A comprehensive review of literature. Bosnian Journal of Basic Medical Sciences. 2017;17:1-8.

12. Bagheri A, Rafati N, Salim RE, Yazdani S. Free-floating pyogenic granuloma of the lacrimal sac. Orbit. 2014;33:156-158.

13. Bacon CM, Du MQ, Dogan AJ. Mucosa-associated lymphoid tissue (MALT) lymphoma: a practical guide for pathologists. Journal of Clinical Pathology. 2007;60:361-372.

14. Boyd SD, Natkunam Y, Allen JR, Warnke RA. Selective Immunophenotyping for Diagnosis of B-cell Neoplasms: Immunohistochemistry and Flow Cytometry Strategies and Results. Applied Immunohistochemistry \& Molecular Morphology. 2013;21:116-131.

15. Mikhail M, Michel RP, Chankowsky J, Arthurs B. Epiphora as first presenting sign of primary extranodal NK/T-cell lymphoma of the lacrimal sac. Orbit. 2017;36:19-21.

16. Parikh RR, Moskowitz BK, Maher E, et al. Long-term outcomes and patterns of failure in orbital lymphoma treated with primary radiotherapy. Leukemia \& Lymphoma. 2015;56:1266-70. 